\title{
Knowledge Coherence, Variety and Economic Growth: Manufacturing Evidence from Italian Regions.
}

Francesco Quatraro ${ }^{\mathrm{a}, \mathrm{b}, \mathrm{c}^{*}}$

a) University of Nice Sophia Antipolis

CNRS-GREDEG

250, rue Albert Einstein

06560 Valbonne

France

b) Department of Economics "S. Cognetti de Martiis"

University of Turin

c) Bureau of Research on Innovation, Complexity and Knowledge (BRICK)

Collegio Carlo Alberto, Moncalieri (Torino)

\begin{abstract}
This paper elaborates a view on knowledge as the result of a combinatorial search activity, so as to investigate its effects on economic growth at the regional level. Empirical estimations corroborate the hypothesis that knowledge coherence and variety, besides the traditional measure of knowledge stock, matter in shaping regional economic performances. The check for spatial dependence suggests that cross-regional externalities exert additional triggering effects on growth, without debasing the effects of knowledge properties. Important policy implications stem from the analysis, in that regional innovation strategies should be carefully coordinated so as to reach a higher degree of internal coherence and trigger economic performances.
\end{abstract}

Keywords: Recombinant Knowledge, Coherence, Variety, Regional growth

JEL Classification Codes: O33, R11

\footnotetext{
* Corresponding author at: GREDEG, CNRS and University of Nice Sophia Antipolis, 250 rue Albert Einstein, 06560 Valbonne, France. Tel. +33 4 93954222; Fax: +33 4 93653798. Email address:

francesco.quatraro@unito.it.
} 


\section{Introduction}

Since the seminal contributions by Nelson (1959) and Arrow (1962), knowledge has attracted more and more the attention of economists, both with respect to the mechanisms leading to its production, dissemination and exchange, and with respect to its effects on productivity.

Despite this, empirical contributions estimating the effects of knowledge on economic growth has appeared only after the path-breaking works by Zvi Griliches (1979). Within this strand of literature, the traditional production function has been extended so as to include knowledge as an additional input. Knowledge is conceived as a bundled stock, as if it were the outcome of a quite homogenous and fluid process of accumulation made possible by R\&D investments, the same way as capital stock ${ }^{1}$.

Empirical analyses at the regional level have instead appeared quite recently. These mainly focus on the determinants of cross-regional differences in the efficiency of knowledge creation, like knowledge spillovers and spatial proximity, within the context of a knowledge production function approach (Acs et al., 2002; Fritsch, 2002 and 2004; Fritsch and Franke, 2004; Crescenzi et al., 2007).

Yet, to the best of author's knowledge, no empirical investigations can be found in literature analyzing the effects of technological knowledge on regional growth.

This paper aims at bringing technological knowledge into an empirical framework analyzing the determinants of cross-regional differential growth rates. To this purpose, we consider technological knowledge as the outcome of a combinatorial search activity carried

\footnotetext{
${ }^{1}$ Without pretending to be exhaustive, out of the noteworthy contributions at the firm level one may look at Nadiri (1980), Griliches (1984), Cuneo and Mairesse (1984), Patel and Soete (1988), Verspagen (1995) and Higón (2007). Studies at the country level include Englander and Mittelstädt (1988), Lichtenberg (1992), Coe and Helpman (1995) and Ulku (2007).
} 
out across a technological space in which combinable elements reside (Weitzman, 1998; Fleming, 2001; Fleming and Sorenson, 2001). In this direction we are able to specify a set of properties that can describe the internal structure of the regional knowledge base and that go beyond the traditional measure of knowledge capital stock. Indicators like knowledge coherence and knowledge variety can be calculated by exploiting the information contained in patent documents, and in particular by looking at the co-occurrence of technological classes which patents are assigned to (Saviotti, 2007). While studies can be found investigating these properties at the firm level (Nesta and Saviotti, 2006; Nesta, 2008), and at the sectoral level (Krafft, Quatraro and Saviotti, 2010; Antonelli, Krafft and Quatraro, 2010), there is no empirical evidence at the regional level yet.

Our analysis focuses on the effects of knowledge dynamics on the evolution of the manufacturing sector within Italian regions over the period $1981-2002^{2}$. This appears to be a particularly appropriate context for our purposes. Indeed, the Italian economic structure has long been characterized by a sharp dualism. On the one hand North-West regions were the cradle of modern industrial firms, and during the 1980s the manufacturing sectors had already completed their growth phase, leaving the floor to service industries. On the other hand, North-Eastern-Central (NEC) regions showed a delayed development of manufacturing activities, carried out mostly by small and medium sized enterprises (SMEs) often operating in peculiar economic and social environments (Fuà, 1983). The role of innovation on such cross-regional differences have become the object of empirical analysis only recently, (Quatraro, 2009a and b), and the investigation of knowledge dynamics in this framework may provide useful insights to gain a better understanding.

\footnotetext{
${ }^{2}$ Italian regions present pretty heterogeneous features both from the economic and the social viewpoint. The purpose of this paper is to understand the extent to which differences in regional knowledge bases might be responsible of such economic variety. Of course, this implies that some other factors may interact in explaining the observed variety. The econometric model we will propose is meant to reduce the bias due to omitted variables and spurious relationships.
} 
In this context, the contribution of this paper to the literature is threefold. First, it applies to notion of recombinant knowledge at the regional level, by identifying a set of properties able to define the structure of the architecture of regional knowledge bases. Second, such analysis is relevant for its general implications concerning the relationships between the dynamics of technological knowledge and regional growth, in particular with respect to regional innovation strategies. Finally, it also aims at rejuvenating a field of enquiry which has been lacking appropriate consideration since the 1980s. For this reason, the debate about the economic development of Italian regions has missed the important opportunity of investigating cross-regional differences in the light of the economics of knowledge and innovation.

The rest of the paper is organized as follows. In Section 2 we outline the theoretical framework and propose a model linking regional productivity growth to the characteristics of knowledge base. Section 3 presents the methodology and Section 4 describes the regional knowledge indicators. In section 5 we describe the data sources and provide descriptive statistics for the main variables. Section 6 presents the results of the empirical estimations and an extension to spatial panel data models, while Section 7 provides a discussion of results in the light of the Italian economic history. Finally, conclusions and policy implications follow in Section 8.

\section{The Theoretical Framework}

Innovation and technological change represent the main engine of economic development. This is even more evident in the present context of advanced economies, in which the creation and utilisation of knowledge have become the key factors affecting the competitiveness of firms, regions and countries (Freeman and Soete, 1997). The creation of 
new knowledge indeed brings about new variety within the economic system, providing the basis for restless economic growth (Metcalfe, 2002).

The recombinant knowledge approach provides a far reaching framework to represent the internal structure of regional knowledge bases as well as to enquire into the effects of its evolution. If knowledge stems from the combination of different technologies, knowledge structure can be represented as a web of connected elements. The nodes of this network stand for the elements of the knowledge space that may be combined with one another, while the links represent their actual combinations. The frequency with which two technologies are combined together provides useful information on the basis of which one can characterize the internal structure of the knowledge base according to the average degree of complementarity of the technologies which knowledge bases are made of, as well as to the variety of the observed pairs of technologies. In view of this, the properties of knowledge structure may be made operative through the use of different methodologies, like social network analysis or the implementation of indicators based on co-occurrence matrixes in which rows and columns elements are bits of knowledge, while each cell reports the frequency with which each pair of technologies is observed.

The dynamics of technological knowledge can therefore be understood as the patterns of change in its own internal structure, i.e. in the patterns of recombination across the elements in the knowledge space. This allows for qualifying both the cumulative character of knowledge creation and the key role played by the properties describing knowledge structure, as well as for linking them to the relative stage of development of a technological trajectory (Dosi, 1982; Saviotti, 2004 and 2007; Krafft, Quatraro and Saviotti, 2010). Moreover, the grafting of this approach into the analysis of the determinants of cross-regional growth differentials allows for a better understanding of the interplay of knowledge dynamics and the patterns of regional industrial development. The ability to engage in a search process within 
cognitive spaces that are distant from the original starting point is likely to generate breakthroughs stemming from the combination of brand new components (Nightingale, 1998; Fleming, 2001; Fleming and Sorenson, 2001; Sorenson et al., 2006). In this direction regional innovation capabilities may be defined as the ability of regional actors to engage in the combinatorial process that gives rise to the structure of the regional knowledge base (Lawson and Lorenz, 1999; Romijn and Albu, 2002; Antonelli, 2008).

The economic development of regions is indeed strictly related to the innovative potentials of the industries they are specialized in. Firms within a propulsive industry grow at faster rates, propagating the positive effects across firms directly and indirectly related to the propulsive industry. The potentials for creating new knowledge are at the basis of regional growth, and they happen to be unevenly distributed across sectors according to the relative stage of lifecycle (Perroux, 1955; Kuznets, 1930; Burns, 1934; Schumpeter, 1939) ${ }^{3}$.

The intertwining of industrial and technological lifecycles is therefore of great importance, as well as the distinction between exploration and exploitation (March, 1991). The introduction of new technologies is indeed more likely to show a boosting effect on economic performances as long as the search activity enters an exploitation stage wherein potential dominant designs are selected and implemented. The creation of new knowledge in this phase, and hence the resulting knowledge base, is more likely to involve by the recombination of knowledge bits characterized by a great deal of complementarity and by the identification of diverse and yet highly related knowledge bits. A further dichotomy between random screening and organized search seems to be relevant in this direction. The transition to organized search is typical of phases in which profitable technological trajectories have been identified, and the recombination activity occurs out of a sharply defined region of the

\footnotetext{
${ }^{3}$ Thomas (1975) articulated the implications of Perroux' framework on regional economic growth using a product life-cycle perspective, wherein the saturation of product markets are the main responsible for the slowdown of growth rates and the quest for innovations aims at opening new markets.
} 
knowledge space. The likelihood of successful innovations is greater in this stage, and marks the difference between mature and growing sectors (Krafft, Quatraro and Saviotti, 2010 and 2011).

\subsection{The model}

The discussion conducted above leads us to propose a simple model to appreciate the effects of the properties of knowledge structure on regional economic growth:

$$
g_{i, t}=f\left(K_{i, t-1}\right)
$$

Where subscripts $i$ and $t$ refer respectively to the region and to time, $g$ is the growth rate of productivity and $K$ is the regional knowledge base. Traditionally, $K$ is defined as the stock of knowledge corrected for technical obsolescence: $K_{i, t}=\dot{k}_{i, t}+(1-\delta) K_{i, t-1}$, where $\dot{k}_{i, t}$ is the flow of new knowledge at time $t$ and $\delta$ is the rate of obsolescence. This relationship is able to capture the influence only of intangible capital, neglecting the characteristics of regional knowledge.

In order to appreciate the implications of the recombinant knowledge approach on the operationalization of the properties of knowledge structure, the $K$ term of Equation (1) can be modelled by extending to the regional domain the framework that Nesta (2008) develops at firm level. Let us recall the main passages in what follows.

Assume that a region is a bundle of $D$ productive activities, represented by the vector $P=\left[p_{1}, \ldots, p_{d}, \ldots, p_{D}\right]$. Each regional activity $p_{d}$ draws mainly upon a core scientific and technological expertise $e_{d}$, so that the regional total expertise is the vector $E=\left[e_{1}, \ldots, e_{d}, \ldots, e_{D}\right]$. The regional knowledge base emerges out of a local search process aimed at combining different and yet related technologies. This implies that an 
activity $p_{d}$ may also take advantage of the expertise developed in other activities $l(l \neq d)$, depending on the level of relatedness $\tau$ between the technical expertise $e_{d}$ and $e_{l}$. It follows that the knowledge base $k$ used by the $d$ th activity is:

$k_{d} \equiv e_{d}+\sum_{l \neq d}^{D} e_{l} \tau_{l d}$

The meaning of Equation (2) is straightforward. The knowledge base $k$ of each activity $d$ amounts to the sum of its own expertise and the expertise developed by other activities weighted by their associate relatedness. Such equation can be generalized at the regional level to define the aggregate knowledge base:

$K \equiv \sum_{d}^{D} e_{d}+\sum_{d}^{D} \sum_{l \neq d}^{D} e_{l} \tau_{l d}$

Let us assume that $\tau_{l d}$ is constant across activities $d$ and $l$, so that $\tau_{l d}=R$ across all productive activities within the region. Since $\sum_{d}^{D} e_{D}$ is the regional knowledge stock $(E)$, Equation (3) boils down to:

$$
K \equiv E[1+(D-1) R]
$$

According to Equation (4), the regional knowledge is a function of i) the knowledge capital stock, ii) the number of technologies residing in the region, and iii) the coherence $(R)$ among activities. If the bundle of activities residing within the region are characterized by a high degree of coherence $(R>0)$, then the aggregate knowledge base increase with the variety of technological competences $(D)$, weighted by their average relatedness. Conversely, if regional activities are featured by no coherence $(R=0)$, then the regional knowledge base is equal to the knowledge capital stock. Therefore, the traditional approach to the computation of the knowledge base turns out to be a special case where $R=0$. Equation (4) can be approximated as follows:

$K \cong E D R$ 
Substituting Equation (5) in (1) we therefore get:

$g_{i, t}=f\left(E_{i, t-1} D_{i, t-1} R_{i, t-1}\right)$

In view of the arguments elaborated so far we are now able to spell out our working hypotheses. The generation of new knowledge is a core activity strategic for the competitive advantage of regional economies. Cross-regional differences in the development of technological knowledge provide thus a possible, although not exhaustive, explanation for differential growth rates (Fagerberg, 1987, Maleki, 2000). In line with a well established tradition of analysis we therefore expect $E$ to be positively related to productivity growth.

The creation of technological knowledge is likely to exert a triggering effect on regional economic growth. Traditional analyses of the relationships between knowledge and growth has viewed the former as a bundled stock, i.e. a sort of black box the dynamics of which are rather obscure. Recent advances in the understanding of the cognitive mechanisms underlying the process of knowledge production allows for proposing that knowledge is the outcome of a combinatorial activity. Agents undertake their search across a bounded area of the knowledge landscape, so as to identify combinable pieces of knowledge. In other words, recombinant knowledge is the outcome of a local search process.

Knowledge structure may therefore be represented as a network, the nodes of which represent the combinable technologies, while links represent the actual combinations. Regional knowledge base turns out to be featured by a fairly heterogeneous structure, rather than a bundled stock. Due to the local character of search, the positive effects of knowledge on productivity which stem from the recombination of different technologies, are more likely to occur in contexts where agents are able to combine together different and yet complementary technologies. Conversely, the presence of activities based upon weak complementarity of technological competences makes it difficult to implement effective knowledge production. In this case knowledge dynamics may hardly trigger regional growth. 
Therefore, in order to foster productivity growth, the internal structure of regional knowledge ought to be characterized by a high degree of complementarity across technologies. The specialization in technological activities undergoing organized search strategies is thus likely to trigger regional economic performances and as a consequence knowledge coherence $(R)$ is expected to positively affect productivity growth.

Knowledge structure is not supposed to be stable over time. Changes may be brought about by trying new combinations among technologies or by introducing brand new technologies within regional competences. Variety may turn out to be a key resource to the creation of new knowledge, and therefore to economic development. It is indeed related to the technological differentiation within the knowledge base, in particular with respect to the diverse possible combinations of pieces of knowledge in the regional context. The localness degree of search implies that variety is likely to engender sensible results in terms of knowledge creation when such diverse technologies are somehow related one another. Within an established technological trajectory, the combination of technologies that are unrelated is less likely to enhance the process of knowledge creation, and hence it is not expected to contribute economic growth. The expectation about $D$ therefore depends very much on the qualification of the variety of combined elements. Within contexts featured by organized search strategies within selected technological trajectories, related variety is likely to dominate over unrelated variety. The combination of a variety of related technologies is likely to exert a positive effect on knowledge production, and hence growth, while the combination of unrelated technologies is likely to exert a negative effect on knowledge production, and hence on regional growth. 


\section{Methodology}

In order to investigate the effects of the properties of regional knowledge base on productivity growth, we first calculate an index of multi factor productivity (MFP) ${ }^{4}$. To this purpose we follow a standard growth accounting approach (Solow, 1957; Jorgenson, 1995; OECD, 2001). Let us start by assuming that the regional economy can be represented by a general Cobb-Douglas production function with constant returns to scale:

$Y_{i t}=A_{i t} C_{i t}^{\alpha_{i t}} L_{i t}^{\beta_{i t}}$

where $L_{i t}$ is the total hours worked in the region $i$ at the time $t, C_{i t}$ is the level of the capital stock in the region $i$ at the time $t$, and $A_{i t}$ is the level of MFP in the region $i$ at the time $t$.

Following Euler's theorem, output elasticities have been calculated (and not estimated) using accounting data, by assuming constant returns to scale and perfect competition in both product and factors markets. The output elasticity of labour has therefore been computed as the factor share in total income:

$$
\begin{aligned}
& \beta_{i, t}=\left(w_{i, t} L_{i, t}\right) / Y_{i, t} \\
& \alpha_{i, t}=1-\beta_{i, t}
\end{aligned}
$$

Where $w$ is the average wage rate in region $i$ at time $t$. Thus we obtain elasticities that vary both over time and across regions.

Then the discrete approximation of annual growth rate of regional TFP is calculated as usual in the following way:

\footnotetext{
${ }^{4}$ Some basic questions of course remain as to what interpretations to give to these kinds of index. While Solow (1957) associated TFP growth with technological advances, Abramovitz (1956) defined the residual as some sort of measure of ignorance. Nonetheless it remains a useful signalling device, in that it provides useful hints on where the attention of the analysts should focus (Maddison, 1987).
} 


$$
\ln \left(\frac{A_{i}(t)}{A_{i}(t-1)}\right)=\ln \left(\frac{Y_{i}(t)}{Y_{i}(t-1)}\right)-(1-\bar{\beta}) \ln \left(\frac{C_{i}(t)}{C_{i}(t-1)}\right)-\bar{\beta} \ln \left(\frac{L_{i}(t)}{L_{i}(t-1)}\right)
$$

The basic hypothesis of this paper is that differences in regional growth rates are driven by the characteristics of regional knowledge bases. The increase in the knowledge stock and in the knowledge coherence is likely to positively affect productivity growth, while the effects of variety are likely to depend on the degree to which the diverse technological competences are related one another.

The test of such hypothesis needs for modelling the growth rate of MFP as a function of the characteristics of the knowledge base. Moreover, as is usual in this kind of empirical settings, we include in the structural equation also the lagged value of MFP, $\ln A_{i, t-1}$, in order to capture the possibility of mean reversion. Therefore the econometric specification of Equation (6) becomes:

$$
\ln \left(\frac{A_{i}(t)}{A_{i}(t-1)}\right)=a+b \ln A_{i, t-1}+c_{1} \ln E_{i, t-1}+c_{2} \ln D_{i, t-1}+c_{3} \ln R_{i, t-1}+\rho_{i}+\sum \psi t+\varepsilon_{i, t}
$$

Where the error term is decomposed in $\rho_{i}$ and $\Sigma \psi t$, which are respectively region and time effects, and the error component $\varepsilon_{i t}$. Equation (11) can be estimated using traditional panel data techniques implementing the fixed effect estimator. It relates the rates of productivity growth to the characteristics of knowledge base. However, one needs also to control for the impact on the one hand of agglomeration economies, on the other hand of changing regional industrial specialization, so as to rule out the possibility that such effects are somehow captured by the knowledge-related variables. In view of this, we can write Equation (11) as follows:

$$
\begin{aligned}
& \ln \left(\frac{A_{i}(t)}{A_{i}(t-1)}\right)=a+b \ln A_{i, t-1}+c_{1} \ln E_{i, t-1}+c_{2} \ln D_{i, t-1}+c_{3} \ln R_{i, t-1}+ \\
& +c_{4} A G G L_{t-1}+c_{5} L O Q_{t-1}+\rho_{i}+\sum \psi t+\varepsilon_{i, t}
\end{aligned}
$$


Productivity growth rates depend now not only on knowledge capital stock, variety and coherence (respectively $E, D$ and $R$ ). Following Crescenzi et al. (2007), the effects agglomeration economies are captured by the variable $A G G L$, which is calculated as the $(\log )$ ratio between regional population and size (square kilometres). The changing specialization is instead proxied by $L O Q$, i.e. the location quotient for manufacturing added value.

\subsection{Panel Data and Spatial Dependence}

The analysis of the effects of knowledge on productivity growth at the regional level calls for a special focus on the geographical attributes of such relations, i.e. on location aspects. Regional scientists have indeed showed that geographical proximity may affect correlation between economic variables.

While the traditional econometric approach has mostly neglected this problem, a new body of literature has recently developed, dealing with the identification of estimators able to account for both spatial dependence between the relationships between observations and spatial heterogeneity in the empirical model to be estimated. Former treatment of spatial econometric issues can be found in Anselin (1988), subsequently extended by Le Sage (1999).

The idea behind the concept of spatial dependence is straightforward. The properties of economic and social activities of an observed individual are likely to influence economic and social activities of neighbour individuals. Formally this relationship can be expressed as follows:

$$
y_{i, t}=h\left(y_{j, t}\right), i=1, \ldots, n, j \neq i
$$

The dependence can therefore be among several observations. If this is the case, structural forms like equation (12) are likely to produce a bias in the estimation results. There are different ways to cope with this issue. First, one may apply spatial filters to the sample 
data, so as to remove the spatial structure and then apply traditional estimation techniques. Second, the relationship can be reframed using a spatial error model (SEM), in which the error term is further decomposed so as to include a spatial autocorrelation coefficient. Third, one may apply the spatial autoregressive model (SAR), which consists of including the spatially lagged dependent variable in the structural equation.

We decided to compare the SAR and SEM models in order to have a direct assessment of the spatial dependence of productivity growth between close regions. However, most of the existing literature on spatial econometrics propose estimator appropriate for cross-sectional data. Given the panel data structure of our sample, we therefore follow Elhorst (2003) extending Equation (12) so as to obtain the SAR (Eq. 14) and the SEM (Eq. 15) specifications:

$$
\begin{aligned}
& \ln \left(\frac{A_{i}(t)}{A_{i}(t-1)}\right)=\xi W \ln \left(\frac{A_{i}(t)}{A_{i}(t-1)}\right)+b \ln A_{i, t-1}+c_{1} \ln E_{i, t-1}+ \\
& +c_{2} \ln D_{i, t-1}+c_{3} \ln R_{i, t-1}+c_{4} A G G L_{t-1}+c_{5} L O Q_{t-1}+\rho_{i}+\sum \psi t+\varepsilon_{i, t} \\
& \ln \left(\frac{A_{i}(t)}{A_{i}(t-1)}\right)=b \ln A_{i, t-1}+c_{1} \ln E_{i, t-1}+c_{2} \ln D_{i, t-1}+c_{3} \ln R_{i, t-1}+ \\
& +c_{4} A G G L_{t-1}+c_{5} L O Q_{t-1}+\rho_{i}+\sum \psi t+\varepsilon_{i, t}+\phi_{t}
\end{aligned}
$$

$$
\phi_{t}=\delta W \phi_{t}+\mu_{t}, E\left(\mu_{t}\right)=0, E\left(\mu_{t} \mu_{t}^{\prime}\right)=\sigma^{2} I_{N}
$$

Where $\xi$ is referred to as spatially autoregressive coefficient and $W$ is a weighting matrix. This latter can be defined either as a contiguity or as a normalized distance matrix. In the analysis that follows we chose the second alternative, by building a 19x19 symmetric matrix reporting the distance in kilometres among the city centre of the regional chief towns.

\section{The Implementation of Regional Knowledge Indicators}

The implementation of regional knowledge indicators rests on the recombinant knowledge approach and on the model elaborated in Section 2. In order to provide an 
operational translation of such variables one needs to identify both a proxy for the bits of knowledge and a proxy for the elements that make their structure. For example one could take scientific publications as a proxy for knowledge, and look either at keywords or at scientific classification (like the JEL code for economists) as a proxy for the constituting elements of the knowledge structure. Alternatively, one may consider patents as a proxy for knowledge, and then look at technological classes to which patents are assigned as the constituting elements of its structure, i.e. the nodes of the network representation of recombinant knowledge. In this paper we will follow this latter avenue ${ }^{5}$. Each technological class $j$ is linked to another class $m$ when the same patent is assigned to both of them. The higher is the number of patents jointly assigned to classes $j$ and $m$, the stronger is this link. Since technological classes attributed to patents are reported in the patent document, we will refer to the link between $j$ and $m$ as the co-occurrence of both of them within the same patent document $^{6}$. We may now turn to explain how knowledge characteristics may be translated into computable variables.

1) Let us start by the traditional regional knowledge stock. This is computed by applying the permanent inventory method to patent applications. We calculated it as the cumulated stock of past patent applications using a rate of obsolescence of $15 \%$ per

\footnotetext{
${ }^{5}$ The limits of patent statistics as indicators of technological activities are well known. The main drawbacks can be summarized in their sector-specificity, the existence of non patentable innovations and the fact that they are not the only protecting tool. Moreover the propensity to patent tends to vary over time as a function of the cost of patenting, and it is more likely to feature large firms (Pavitt, 1985; Griliches, 1990). Nevertheless, previous studies highlighted the usefulness of patents as measures of production of new knowledge, above all in the context of analyses of innovation performances at the regional level. Such studies show that patents represent very reliable proxies for knowledge and innovation, as compared to analyses drawing upon surveys directly investigating the dynamics of process and product innovation (Acs et al., 2002). Besides the debate about patents as an output rather than an input of innovation activities, empirical analyses showed that patents and R\&D are dominated by a contemporaneous relationship, providing further support to the use of patents as a good proxy of technological activities (Hall et al., 1986). Moreover, it is worth stressing that our analysis focuses on the dynamics of manufacturing sectors.

${ }^{6}$ It must be stressed that to compensate for intrinsic volatility of patenting behaviour, each patent application is made last five years.
} 
annum: $E_{i, t}=\dot{h_{i, t}}+(1-\delta) E_{i, t-1}$, where $\dot{h}_{i, t}$ is the flow of regional patent applications and $\delta$ is the rate of obsolescence ${ }^{7}$.

2) As for the properties of knowledge we are interested in, we decided to measure $D$ (variety) in regional knowledge by using the information entropy index. Entropy measures the degree of disorder or randomness of the system, so that systems characterized by high entropy will also be characterized by a high degree of uncertainty (Saviotti, 1988).

Such index was introduced to economic analysis by Theil (1967). Its earlier applications aimed at measuring the diversity degree of industrial activity (or of a sample of firms within an industry) against a uniform distribution of economic activities in all sectors, or among firms (Attaran, 1985; Frenken et al., 2007; Boschma and Iammarino, 2009).

Differently from common measures of variety and concentration, the information entropy has some interesting properties (Frenken, 2004). An important feature of the entropy measure, which we will exploit in our analysis, is its multidimensional extension. Consider a pair of events $\left(\mathrm{X}_{\mathrm{j}}, \mathrm{Y}_{\mathrm{m}}\right)$, and the probability of co-occurrence of both of them $p_{j m}$. A two dimensional (total) entropy measure can be expressed as follows (region and time subscripts are omitted for the sake of clarity):

$$
H(X, Y)=\sum_{j=1}^{q} \sum_{m=1}^{w} p_{j m} \log _{2}\left(\frac{1}{p_{j m}}\right)
$$

If one considers $p_{j m}$ to be the probability that two technological classes $j$ and $m$ co-occur within the same patent, then the measure of multidimensional entropy focuses on the variety of co-occurrences of technological classes within regional patents applications.

\footnotetext{
${ }^{7}$ Different depreciation rates have been implemented, which provided basically similar results.
} 
Moreover, the total index can be decomposed in a "within" and a "between" part anytime the events to be investigated can be aggregated in a smaller numbers of subsets. Within-entropy measures the average degree of disorder or variety within the subsets, while between-entropy focuses on the subsets measuring the variety across them. It can be easily shown that the decomposition theorem holds also for the multidimensional case. Hence if one allows $j \in S_{g}$ and $m \in S_{z}(g=1, \ldots, \mathrm{G} ; z=1, \ldots, \mathrm{Z})$, we can rewrite $H(X, Y)$ as follows:

$H(X, Y)=H_{Q}+\sum_{g=1}^{G} \sum_{z=1}^{Z} P_{g z} H_{g z}$

Where the first term of the right-hand-side is the between-group entropy and the second term is the (weighted) within-group entropy. In particular:

$$
\begin{aligned}
& H_{Q}=\sum_{g=1}^{G} \sum_{z=1}^{Z} P_{g z} \log _{2} \frac{1}{P_{g z}} \\
& P_{g z}=\sum_{j \in S_{g}} \sum_{m \in S_{Z}} p_{j m} \\
& H_{g z}=\sum_{j \in S_{g}} \sum_{m \in S_{z}} \frac{p_{i j}}{P_{g z}} \log _{2}\left(\frac{1}{p_{j m} / P_{g z}}\right)
\end{aligned}
$$

Following Frenken et al. (2007), we can refer to between-group and withingroup entropy respectively as unrelated technological variety (UTV) and related technological variety $(R T V)$, while total information entropy is referred to as general technological variety $(T V)$. The distinction between related and unrelated variety is based on the assumption that any pair of entities included in the former generally are more closely related, or more similar to any pair of entities included in the latter. This assumption is reasonable when a given type of entity (patent, industrial sector, trade categories etc.) is organized according to a hierarchical classification. In this case each 
class at a given level of aggregation contains "smaller" classes, which, in turn contain yet "smaller" classes. Here, small refers to a low level of aggregation.

We can reasonably expect then that the average pair of entities at a given level of aggregation will be more similar than the average pair of entities at a higher level of aggregation. Thus, what we call related variety is measured at a lower level of aggregation (3 digit class within a 1 digit macro-class) than unrelated variety (across 1 digit macro-classes). This distinction is important because we can expect unrelated (or inter-group) variety to negatively affect productivity growth, while related (or intragroup) variety is expected to be positively related to productivity growth. Moreover, the evolution of total variety is heavily influenced by the relative dynamics of related and unrelated variety, such that if unrelated variety is dominant the effects of total variety on productivity growth can be expected to be negative, while the opposite holds if related technological variety dominates the total index (Krafft, Quatraro, Saviotti, 2010).

3) Third, we calculated the coherence $(R)$ of the regional knowledge base, defined as the average complementarity of any technology randomly chosen within a region with respect to any other technology (Nesta and Saviotti, 2005 and 2006; Nesta, 2008).

To yield the knowledge coherence index, a number of steps are required. In what follows we will describe how to obtain the index at the regional level. First of all, one should calculate the weighted average relatedness $W A R_{i}$ of technology $i$ with respect to all other technologies present within the sector. Such a measure builds upon the measure of technological relatedness $\tau$, which is introduced in Appendix A. Following Teece et al. (1994), $W A R_{j}$ is defined as the degree to which technology $j$ is related to all other technologies $m \neq j$ within the region $i$, weighted by patent count $P_{\text {mit }}$ : 
$W A R_{j i t}=\frac{\sum_{m \neq j} \tau_{j m} P_{m i t}}{\sum_{m \neq i} P_{m i t}}$

Finally the coherence of knowledge base within the region is defined as weighted average of the $W A R_{j i t}$ measure:

$$
R_{i t}=\sum_{j \neq m} W A R_{j i t} \times \frac{P_{j i t}}{\sum_{j} P_{j i t}}
$$

This measure captures the degree to which technologies making up the regional knowledge base are complementary one another. The relatedness measure $\tau_{j m}$ indicates indeed that the utilization of technology $j$ implies that of technology $m$ in order to perform specific functions that are not reducible to their independent use. This makes the coherence index appropriate for the purposes of this study.

\section{The Data}

In this paper we investigate the relationship between productivity growth and regional knowledge in Italian regions ${ }^{8}$. The data we used have been drawn from two main sources. We employed data from the regional accounts provided by the Italian Institute of Statistics (ISTAT) to calculate the MFP index. We used real GDP (1995 constant prices) as a measure of regional output, regional labour income to compute the output elasticity of labour, regional employment level as a proxy for labour input, real gross fixed investments to derive capital stock (see Appendix B).

\footnotetext{
${ }^{8} \mathrm{We}$ acknowledge that the use of administrative regions to investigate the effects of knowledge creation represents only an approximation of the local dynamics underpinning such process. Indeed administrative borders are arbitrary, and therefore might not be representative of the spontaneous emergence of local interactions. It would be much better to investigate these dynamics by focusing on local systems of innovation. However, it is impossible to find out data at such a level of aggregation. Moreover, the identification of local systems involve the choice of indicators and threshold values according to which one can decide whether to unbundle or not local institutions. This choice is in turn arbitrary, and therefore it would not solve the problem, but it would only reproduce the issue at a different level. Thus we think that despite the unavoidable approximation, our analysis may provide useful information on the dynamics under scrutiny.
} 
To calculate the measures of regional knowledge base we employed an original dataset of patent applications submitted to the European Patent Office, as proxy of technological activities within manufacturing sectors. Each patent is assigned to a region, on the basis of the inventors' addresses ${ }^{9}$. Detailed information about the patents' contents has been drawn from the Thomson Derwent World Patent Index®. Each patent is classified in different technological field according to the Derwent classification. All technologies are covered by 20 subject areas designated as follows: classes $\mathrm{A}$ to $\mathrm{M}$ are in chemicals, $\mathrm{P}$ to $\mathrm{Q}$ refer to engineering, $\mathrm{S}$ to $\mathrm{X}$ refer to Electrical and Electronic. Each of the subject areas is in turn subdivided into 3-digit classes.

We used the 3-digit classification to calculate both knowledge coherence and information entropy. The decomposition of the entropy measure has been conducted by considering the subject areas as subsets, so as to obtain information entropy both 'within' and 'between' subject areas.

The initial patent dataset consists of 55377 observations and 336 3-digit classes spread across 19 regions over the period ranging from 1979 to 2003. After the calculations we ended up with a vector of five knowledge variables, observed for each region over the time period 1981 - 2002. Such vector has then been matched with the vector of regional productivity growth rates over the same period for the corresponding regions.

Table 1 and 2 provide the descriptive statistics for the set of variables used in the analysis and show general information about the various sampled regions. The sample is

\footnotetext{
${ }^{9}$ The assignment of patent to regions on the basis of inventors' addresses is the most widespread practice in the literature (see for example Maurseth and Verspagen, 2002; Henderson et al., 2005; Breschi and Lissoni, 2009, Paci and Usai, 2009, to quote a few). A viable alternative may rest on the use of applicants' addresses, above all when the assessment of knowledge impact on growth is at stake (see Antonelli, Krafft and Quatraro, 2010). However, when the analysis is conducted at local level of aggregation, and the geography of collective processes of knowledge creation is emphasized, the choice of inventors' addresses remains the best one.
} 
made of 19 Italian regions ${ }^{10}$ and is characterized by a high degree of variance for what concerns both the knowledge variables and the growth rates of multi factor productivity.

\section{>>INSERT TABLES 1 AND 2 ABOUT HERE $<<<~$}

In particular, from Table 2 it seems to emerge an interesting pattern of geographical distribution for the knowledge variables. For example, while we expected negative values for knowledge coherence in North-Western regions, similar evidence for some North-Eastern regions is slightly puzzling. Negative values of knowledge coherence are indeed to be associated with periods of random screening in research activities, typical of exploration stages. Innovation systems featured by the predominance of a mature paradigm are likely to undertake research efforts along a variety of paths, unless new profitable fields are sorted out, leaving room to the exploitation stage (and the consequent rise in knowledge coherence). The evidence for regions like Emilia Romagna and Tuscany suggests therefore that their industrial and technological development is more similar to that of North-Western regions than to that of North-East, maybe due to their faster growth patterns during the 1980s.

\section{Empirical Results}

In order to assess the effects of knowledge coherence and variety on regional productivity growth, we carried out a fixed-effect panel data estimation of Equation (12), which is reported in table 3. Different estimations are shown, in which we consider alternatively $T V, R T V$ and $U T V$. The first column shows the results for the estimation including the measure of general technological variety. The results are quite in line with what expected according to our working hypotheses. Firstly, cross regional differences in the accumulation of knowledge capital stock matter in explaining productivity differentials, as is shown by the positive and significant coefficient on the variable $E$. Secondly, knowledge capital stock is not sufficient to characterize the production of knowledge at the regional level.

\footnotetext{
${ }^{10} \mathrm{We}$ left out the Molise region due to very low levels multi-technologies patents.
} 
It is important to account also for qualitative changes in the knowledge base. In this direction, the internal degree of coherence of regional knowledge base exhibits a positive and significant coefficient. The more related are the diverse technological activities carried out within the region, the higher the rates of productivity growth. Dynamic economies of scope are at stake as long as they are searched through the combination of close technologies. Finally, variety is a measure of how much the system is able to develop new technological opportunities, and eventually foster economic growth. As expected, the coefficient of $T V$ is positive and significant. For what concerns our control variable, it must be stressed that the proxy for agglomeration economies is not significant, while the location quotient for manufacturing activities is, as one could expect, negative and significant.

Column (2) reports the results for the estimation including UTV. Also in this case the coefficient for knowledge capital is positive and significant, like the one for knowledge coherence. For what concerns variety, our estimations show that $U T V$ is not likely to exert statistically significant effects on regional productivity growth. Also in this case the only significant control variable is the location quotient, which shows a negative sign.

\section{INSERT TABLE 3 ABOUT HERE}

The estimation in column (3) takes account of $R T V$. Differently from the other estimations, the coefficient for the lagged levels of productivity is now (weakly) significant, and with positive sign. For what concerns the effects of knowledge capital, the results are well in line with what we have seen so far. The coefficient is indeed positive and significant. The same applies to knowledge coherence. Not surprisingly, the coefficient for $R T V$ is positive and statistically significant. This means that the positive effects observed in the case of $T V$ is driven by $R T V$. Econometric results in column (4), where $U T V$ and $R T V$ are put together, are coherent with column (3). Knowledge coherence affects positively productivity growth, as 
well as knowledge capital. Again, only $R T V$ appears to significantly affect productivity growth.

The results showed so far provide interesting evidence about the effects of regional knowledge base on productivity dynamics. However, recent advances in the analysis of spatial economic dynamics have pointed to the importance of proximity among economic agents. While the focus on the regional level does not allow for investigating this issue from a microeconomic viewpoint, nonetheless the presence of cross-regional external economies may cause a bias in the estimation using techniques that do not account for spatial dependence.

Table 4 reports the results from the econometric estimation of the SAR model (Equation (14)). For the sake of homogeneity, different models have been estimated, including alternatively $T V, R T V$ and $U T V$. As is immediately clear, the inclusion of the spatially lagged dependent variable changes our results only to a very limited extent. Let us start from column (1). First of all, the coefficient for the spatially lagged variable is positive and significant. The coefficients of both knowledge capital and knowledge coherence are significant and, as expected, positive. Interestingly enough, the coefficient for $T V$ is no longer statistically significant. This might be explained by arguing that the positive coefficient of variety observed in the standard fixed-effects estimations, captures the effects of stimuli coming from outside the region. For what concerns the control variables, it may be noted that the location quotient shows also in this case a negative and significant coefficient. Differently from the previous estimates, the coefficient for agglomeration is now negative and statistically significant. Such result also finds explanation in the peculiarity of industrial development paths followed by Italian regions ${ }^{11}$.

\section{INSERT TABLE 4 ABOUT HERE}

\footnotetext{
${ }^{11}$ Population density is indeed likely to be higher in early-industrialized areas in the North-West, while lateindustrialized regions in the so-called 'third Italy' were characterized by lower population density due to diffusion of population across larger areas rather than its concentration within metropolitan cities.
} 
Columns (2) and (3) include respectively $U T V$ and $R T V$. The results are fairly persistent, in that still knowledge capital and coherence are positive and significant, while none of the two variety measures turn out to be significant. Once again, the spatially lagged dependent variable exhibits a positive and significant coefficient, while both the control variables negatively affect regional productivity growth. Finally, the estimation in column (4) includes related and unrelated variety together, providing results consistent with the previous estimations.

In order to check for the robustness of our results, we present in table 5 the results for the estimation of the SEM model (Equation (15)). The results are basically the same across the four models estimated, and are very coherent with the SAR estimations. The effects of variety are statistically significant in none of the models, while knowledge capital and knowledge coherence confirm to positively and significantly affect regional productivity growth. Both agglomeration and the relative location quotient show negative and significant coefficients, supporting the relevance of the idiosyncratic features of regional development paths in Italy. Finally, the coefficient for spatial autocorrelation is positive and significant across all the models, corroborating the argument of cross-regional transmission of productivity gains.

\section{INSERT TABLE 5 ABOUT HERE}

Summing up, the check for spatial dependence has provided interesting results with respect to impact of knowledge characteristics on economic growth. In particular, the effects of knowledge coherence appeared to be pretty persistent and robust across the different specifications and the different estimators implemented. The variety of observed combinations instead appears to be somehow neutralized by the spatially lagged dependent variable. This result is not that obvious, and would deserve further investigation. 


\section{Discussion}

The results obtained in this paper open up a new path to the empirical analysis of the determinants of cross-regional growth differentials, with particular respect to the effects of knowledge creation. Moreover, the set of indicators we used in our analysis can be well used to explore the determinants of efficiency of knowledge production processes within a knowledge production function approach.

Besides the theoretical and methodological contribution, the analysis we carried out sheds a new light on the study of regional development in Italy, which has failed to apply the interpretative framework provided by the economics of innovation to investigate crossregional differences in growth patterns. A bit of economic history is in order here to help clarifying this point.

In the 1950s most Italian regions were rural, and populated by a large share of smalland medium-sized enterprises, as opposed to North-Western regions, specialized in manufacturing activities, carried out by large firms. Analyzing the distribution of growth rates and structural change at the regional level in the period 1950-1970, the Ancona School identified and found the clues of a successful diffusion process of manufacturing activities towards such rural regions in the North-East and eventually in Central Italy, along the Adriatic coast. For this reason they proposed to group such regions into a larger macro-area which has been eventually called NEC (North-East-Centre) ${ }^{12}$. At the same time, the growth of manufacturing industries was slowing down in the North-West, wherein the growth of business service industries was already in nuce (Pettenati, 1991; Fuà and Zacchia, 1983).

More recent evidence shows that the Italian economy has retained its delay in the industrialization process also during the last decades of the $20^{\text {th }}$ century. Previous analyses of

\footnotetext{
${ }^{12}$ The grouping of Italian regions is as follows. North-West: Piedmont, Lombardy, Valle d'Aosta and Liguria. North-East: Veneto, Emilia-Romagna, Friuli Venezia-Giulia,Trentino Alto-Adige. Centre: Tuscany, Abruzzi, Marches, Lazio, Umbria and Molise. South: Campania, Apulia, Calabria, Basilicata, Sicilia and Sardegna.
} 
the evolution of the regional specialization index in manufacturing sectors reveal that the geographical pattern has changed significantly over time. Indeed, the North-Eastern and Central regions are characterized by specialization indexes increasing over the period 19812001. It seems that at the turning of the century North-Eastern and Central regions are characterized by specialization indexes very close to (and in the some cases even higher than) the values featuring North-Western regions. Moreover the trend appears to be soundly positive in the former, while the values in the latter are continuously decreasing since the early 1980s (Quatraro, 2009a and 2009b).

\section{INSERT FIGURE 1 ABOUT HERE}

In this direction, the differential specialization of Italian regions in manufacturing sectors seems to produce diverse patterns of growth. The results of our analysis may contribute to better understanding this dynamics. With the help of Figure 1, we may argue that manufacturing sectors in early-industrialized countries have experienced the slackening of growth rates under the period of scrutiny, while early-industrialized regions, i.e. those in the North-East-Centre, have experienced increasing growth rates. Interestingly enough, these positive dynamics seem to have spread along the Adriatic coast to Southern regions. A look at the regional breakdown of knowledge coherence reveals how the index is pretty high in Central Italy and in the South. Out of the North-East regions, the only one showing high values is the Trentino Alto Adige. This would suggest that the main prospects for growth for manufacturing industries are in lagging-behind regions. From a lifecycle perspective, latecomer regions seem to experience manufacturing-based growth dynamics that old industrialized regions have experienced some decades ago. Accordingly, they appear to be in a phase of the technology lifecycle in which new knowledge is produced following rather 
organized search strategies. On the contrary, old industrialized regions face the major challenge to find out new avenues for boosting productivity growth rates. This involves exploration efforts in many possible directions, which look more like a sort of random screening wherein profitable new technologies still has to be found.

While the contribution the such a debate provides an important example of how this framework may be of interest to scholars in regional economics, some limits need to be discussed concerning i) the use of patents to analyze innovation patterns on the one hand, and ii) the extension of Nesta's model to the regional domain on the other hand.

The use of patent applications as a proxy for innovation presents indeed a number of caveats which have already been discussed in Section 5. In addition, their use to analyze the Italian case might provide biased results, due to the size specialization of companies and to the existence of empirical studies emphasizing the scarce propensity of small firms to patent their innovations. It is indeed well known that about the $99 \%$ of Italian firms are small and medium-sized enterprises (SMEs) and this might lead to an underestimation of the phenomenon. However, the issue is far from a clear-cut solution. Empirical contributions in economics have indeed questioned the idea that small firms are more reluctant to innovate. For example, Brower and Kleinknecht (1999) emphasize that small firms develop larger portfolios of patent applications to counterbalance their lower market power. In addition, Lotti and Schivardi (2005) test the existence of a non-linear relationship between size and patent applications, suggesting that both small and large firms patent more than medium-sized ones.

For what concerns the second point, the regional extension of Nesta's model presents pros and cons deserving consideration. While the application of the framework at the firm level has the merit to stress and valorise the heterogeneous nature of firms' competences, an important limit can be identified in the focus on the firm as a single innovating agent, with no emphasis on cross-firm knowledge spillovers. 
The shift to the regional domain is favoured by the consistency of the model with an interpretative framework blending the collective knowledge and the recombinant knowledge approaches. New knowledge stems out of a complex set of interactions among different institutions, of which firms represent only one out of different actors. Such interactions allows for the recombination of bits of knowledge that are fragmented and dispersed among the different agents (Hayek, 1939). The regional glance is thus more appropriate to grasp the local dimension of such dynamics (Antonelli, Patrucco, Quatraro, 2011), so as to investigate the intertwining of the features of the topology of geographical and of knowledge spaces. The architecture of knowledge network, as proxied by the knowledge indicators we described in Section 4, proved to matter in shaping regional growth rates. In particular, the internal coherence of the regional knowledge base is positively related to productivity growth. This is because it is maintained that such index is likely to signal the transition towards a phase of organized search within regional industrial activities. The likelihood of generation of new useful knowledge is higher during this phase, and therefore one expect to also observe positive effects on production processes and hence productivity growth.

A problem might be raised by the framework we developed in this paper, similar to the one we observed to affect Nesta's model. While the regional approach allows for accounting for the dynamics of inter-organizational knowledge flows within local contexts, it risks underestimating the important role of external knowledge as emphasized by Bathelt et al. (2004), who suggest that global pipelines add value to the local buzz by fuelling variety. However, this is not inconsistent with our approach and results. Indeed, while the implementation of spatial econometrics is motivated by the need to reduce the biases emerging when dealing with cross-regional analysis, it also allows us to appreciate and somehow to quantify the effects of productivity dynamics outside the region. By assessing the effects of neighbour regions' productivity we are able to account for the cross-regional effects 
of productivity enhancing factors, of which knowledge dynamics represent the main representatives in our model. The neutralizing effect of the spatial lagged dependent variable on technological variety provides support to this idea ${ }^{13}$, which deserves to be carefully analyzed in future research.

\section{Conclusions}

Innovation and technological knowledge have long been considered as key elements triggering productivity growth. Empirical analyses of this relationship have emerged in the line of Zvi Griliches' extended production function, according to which knowledge has been considered as an additional input in the traditional production function. In this framework knowledge has been considered as a bundled stock, which has been operationalized by applying a sort of permanent inventory method to cumulate an innovation flow measure subject to a depreciation rate.

A step forward is represented by the studies introducing the knowledge production function. This strand of literature has mainly been developed to investigate innovation dynamics at the regional level. Drawing upon the regional innovation systems approach, it has basically provided a former empirical assessment of the degree to which knowledge is the result of the interaction of a number of different and yet complementary institutions involved in innovation activities, like firms, universities, R\&D labs and the like (Cooke et al., 1997; Antonelli, 2008).

While these studies enquired into the determinants of the effectiveness of knowledge production at the regional level, they said very little about the effects of knowledge on

\footnotetext{
${ }^{13}$ The issue of knowledge flows incoming from far areas is more articulated, and difficult to address with the available data. Following Breschi and Lissoni (2001), we acknowledge that when knowledge is at stake, epistemic communities are likely to emerge wherein the effect of geographical distance is mitigated by cognitive proximity. To this purpose, finer-grained information on co-inventorship patterns would be necessary. However, this goes beyond the scope of this paper.
} 
regional growth. Moreover, knowledge kept being represented as a bundled stock, although conceived as stemming from interactive dynamics.

In this paper we have attempted to provide evidence of the effects of knowledge on regional growth by going beyond the traditional representation of knowledge found in literature. The recombinant knowledge approach and its cognitive underpinnings proved to be very fertile in this respect. Knowledge is understood as the result of the combination of bits of knowledge identified in the knowledge space by means of a local search process. This allows for representing the structure of knowledge as a web, the nodes of which are bits of knowledge, while the links stand for their actual combination. Such representation is susceptible of different operational translations. In this paper we have followed the methodology elaborated by Nesta (2008), relying on information provided within patent documents.

We have grafted this methodology into an empirical framework analyzing the effects of the characteristics of knowledge structure on regional productivity growth. Our analysis concerned a sample of 19 Italian regions over the period 1981-2002, focusing on manufacturing sectors. We have calculated annual multifactor productivity growth for each region, and then we have tested the explanatory role of knowledge variables such as the traditional knowledge capital, knowledge coherence and knowledge variety, both related and unrelated.

Summing up, the results of empirical analysis confirm that the regional knowledge base do affect productivity growth rates. In particular, not only the level of knowledge stock matters, but the characteristics of the knowledge base exert also a strong impact. The effects of variety are appreciable when spatial dependence is not accounted for. In particular, we decomposed total variety into related and unrelated variety. We have found that the positive effects of total variety are driven by related variety, while unrelated variety yields not 
significant effects. For what concerns knowledge coherence, its effects are persistent and robust across all the alternative models and estimators implemented. The higher is the internal degree of coherence of knowledge structure, the faster regional productivity is supposed to grow.

Such results have important policy implications, in terms of regional strategies for innovation and knowledge production. The internal coherence of the knowledge base proved indeed to positively affect productivity growth rates. Moreover, the specificity of the Italian case allows also for appreciating the importance of the relative maturity of the main industries, and the linkages between industrial and technology lifecycles. An effective regional innovation strategy should therefore be characterized by a careful assessment of local specificities. The identification of industries which the areas are specialized in is of paramount importance in order to devise the most appropriate incentive schemes. On the one hand, regions dominated by declining industries should be helped to find out new trajectories for development, trying and valorising the existing competences by directing search efforts towards complementary fields. On the other hand, in those regions featured by industries at the frontier, innovation policies might be much more directed towards the generation of incrementally new knowledge drawing upon exploitation strategies.

In conclusion, regional innovation policies should be characterized by intentional and careful coordination mechanisms, able to provide an integrated direction to research and innovation efforts undertaken by the variety of agents that made up the innovation system. The regional production system would then take advantage of a bundle of technological activities showing a high degree of coherence and therefore more likely to be properly absorbed and successfully exploited. 


\section{Acknowledgments}

Part of the background research for this paper has been conducted during my visiting period at Manchester Institute of Innovation Research, University of Manchester. A preliminary version of the paper has been awarded the Salvatore Vinci prize by the University of Naples "Parthenope". Preliminary versions of this paper have been presented at the conference organized by the Regional Studies Association, held in Prague on $27^{\text {th }}-29^{\text {th }}$ May 2008; at the one organized by the European Regional Science Association, held in Liverpool on $27^{\text {th }}-31^{\text {st }}$ August 2008; and at the DIME workshop 'Reconsidering the regional economy' organised at the University of Newcastle on $4^{\text {th }}-5^{\text {th }}$ September 2008. I wish to thank Cristiano Antonelli, Koen Frenken, Lionel Nesta, Dimitri Pontikakis, Andrè Rodriguez-Pose and Allen J. Scott, as well as the two anonymous referees ans the Editor Martin Kenney for their useful comments. I acknowledge the funding of the University of Torino and the Collegio Carlo Alberto as well as the financial support of the European Commission Marie Curie Training Website for the PREPARE summer school on spatial econometrics held in Bratislava in July 2007 and of the French Agence Nationale de la Recherche (contract number: ANR JCJC06_141306, "Knowledge Intensive Sectors: Models and Evidence") and the Provence Alpes Côte d'Azur Region. 


\section{Appendix A}

In order to calculate the knowledge coherence index, it is necessary to define the parameter $\tau$, i.e. technological relatedness, which appears in equation (20). Let us start by calculating the relatedness matrix. The technological universe consists of $k$ patent applications. Let $P_{i k}=1$ if the patent $k$ is assigned the technology $i[i=1, \ldots, \mathrm{n}]$, and 0 otherwise. The total number of patents assigned to technology $i$ is $O_{i}=\sum_{k} P_{i k}$. Similarly, the total number of patents assigned to technology $j$ is $O_{j}=\sum_{k} P_{j k}$. Since two technologies may occur within the same patent, $O_{i} \cap O_{j} \neq \varnothing$, and thus the observed the number of observed cooccurrences of technologies $i$ and $j$ is $J_{i j}=\sum_{k} P_{i k} P_{j k}$. . Applying this relationship to all possible pairs, we yield a square matrix $\Omega(\mathrm{n} \times \mathrm{n})$ whose generic cell is the observed number of co-occurrences:

$$
\Omega=\left[\begin{array}{ccccc}
J_{11} & & J_{i 1} & & J_{n 1} \\
\vdots & \ddots & & & \vdots \\
J_{1 j} & & J_{i j} & & J_{n j} \\
\vdots & & & \ddots & \vdots \\
J_{1 n} & \cdots & J_{i n} & \cdots & J_{n n}
\end{array}\right]
$$

We assume that the number $x_{i j}$ of patents assigned to both technologies $i$ and $j$ is a hypergeometric random variable of mean and variance:

$$
\begin{aligned}
& \mu_{i j}=E\left(X_{i j}=x\right)=\frac{O_{i} O_{j}}{K} \\
& \sigma_{i j}^{2}=\mu_{i j}\left(\frac{K-O_{i}}{K}\right)\left(\frac{K-O_{j}}{K-1}\right)
\end{aligned}
$$

If the observed number of co-occurrences $J_{i j}$ is larger than the expected number of random co-occurrences $\mu_{i j}$, then the two technologies are closely related: the fact the two technologies occur together in the number of patents $x_{i j}$ is not casual. The measure of 
relatedness hence is given by the difference between the observed number and the expected number of co-occurrences, weighted by their standard deviation:

$\tau_{i j}=\frac{J_{i j}-\mu_{i j}}{\sigma_{i j}}$

It is worth noting that such relatedness measure ha so lower and upper bounds: $\left.\tau_{i j} \in\right]-\infty ;+\infty[$. Moreover, the index shows a distribution similar to a t-student, so that if $\left.\tau_{i j} \in\right]-1.96 ;+1.96[$, one can safely accept the null hypothesis of non-relatedness of the two technologies $i$ and $j$. The technological relatedness matrix $\Omega$ ' may hence be thought about as a weighting scheme to evaluate the technological portfolio of regions. 


\section{Appendix B}

In order to calculate the stock of fixed capital at the regional level, we follow the procedure set out by Maffezzoli (2006), which can be summed up as follows. The official procedure to compute the capital stock is the Permanent Inventory Method (PIM). We assume fixed expected service lives, simultaneous exit mortality patterns and linear depreciation. As a consequence, the real gross capital stock can be computed as:

$\tilde{C}_{t}=\sum_{0}^{d-1} I_{t-i}$

Where $d$ is the expected service life, and $I_{t}$ the real investment flow at time $t$. The depreciation of capital stock is simply equal to $D_{t}=\tilde{C}_{t} / d$. The discrete approximation of such a relationship is:

$$
D_{t}=\left(\tilde{C}_{t}+\tilde{C}_{t+1}\right) /(2 d)
$$

Finally the net capital stock obtains directly from $C_{t}=\sum_{i=0}^{d-1} I_{t-1}[1-(2 i+1) / 2 d]$ or via the accumulation equation $C_{t}=C_{t-1}+I_{t}-D_{t}$.

The accounting data at regional level provide series about gross fixed investments. To make calculations of regional capital stocks we drew the capital stock estimations and the depreciation data at the national level. Then we estimated the average expected service life of aggregated assets by rearranging Equation (B2) as follows:

$$
d=\left(\tilde{C}_{t}+\widetilde{C}_{t+1}\right) /\left(2 D_{t}\right)
$$

The results suggest that the aggregate assets are expected to live on average about 34 years. Unfortunately the data about regional accounts are available only starting from 1980, so that we have not enough observation to compute the capital stock. We hence constructed a time series for the actual, time-varying and nation wide depreciation rate, defined as 
$\delta_{t}=D_{t} / K_{t-1}$, and then took the 2001 as a benchmark starting point. We finally extended the series before and after 2001 using the following relationships respectively:

$$
\begin{aligned}
& C_{i, t-1}=\left(C_{i, t}-I_{i, t}\right) /\left(1-\delta_{t}\right) \\
& C_{i, t}=\left(1-\delta_{t}\right) C_{i, t-1}+I_{t}
\end{aligned}
$$

This methodology has some drawbacks, like approximating a linear depreciation scheme with a geometric one, ruling out regional differences in depreciation rates and some necessary degree of measurement error. However, given the availability of the data, it provides a good approximation for the purposes of our work. 


\section{Appendix C}

\section{Corrrelation Matrix}

\begin{tabular}{|c|c|c|c|c|c|c|c|c|}
\hline & $\log A$ & $\log (E)$ & $\log (\mathrm{R})$ & $\log (\mathrm{RTV})$ & $\log (\mathrm{UTV})$ & $\log (\mathrm{TV})$ & $\log (\mathrm{LOQ})$ & $\log (\mathrm{AGGL})$ \\
\hline $\log \mathrm{A}$ & 1 & & & & & & & \\
\hline $\log (E)$ & 0.7156 & 1 & & & & & & \\
\hline $\log (\mathrm{R})$ & -0.4004 & -0.2319 & 1 & & & & & \\
\hline $\log (\mathrm{RTV})$ & 0.2965 & 0.4975 & -0.0499 & 1 & & & & \\
\hline $\log (\mathrm{UTV})$ & 0.5776 & 0.5557 & -0.3998 & 0.1981 & 1 & & & \\
\hline $\log (\mathrm{TV})$ & 0.3894 & 0.7237 & -0.1246 & 0.649 & 0.2283 & 1 & & \\
\hline $\log (\mathrm{LOQ})$ & 0.5542 & 0.2602 & -0.4208 & 0.0721 & 0.6105 & -0.0219 & 1 & \\
\hline $\log (\mathrm{AGGL})$ & 0.5493 & 0.6326 & -0.1183 & 0.4171 & 0.2112 & 0.6627 & -0.0398 & 1 \\
\hline
\end{tabular}




\section{References}

Abramovitz, M., 1956. Resource and output trends in the United States since 1870. American Economic Review 46, 5-23.

Acs, Z.J., Anselin, L. and Varga, A., 2002. Patents and innovation counts as measures of regional production of new knowledge. Research Policy 31, 1069-1085.

Anselin, L., 1988. Spatial Econometrics: Methods and models. Kluwer, Dordrecht..

Antonelli, C., 2008. Localised Technological Change. Towards the Economics of Complexity. Routledge, New York.

Antonelli, C., Krafft, J. and Quatraro, F., 2010. Recombinant knowledge and growth: The case of ICTs. Structural Change and Economic Dynamics 21, 50-69.

Antonelli C., Patrucco P. and Quatraro, F., 2011. Pecuniary knowledge externalities: Evidence from European Regions. Economic Geography, forthcoming.

Arrow, K. J., 1962. Economic welfare and the allocation of resources for invention, in: Nelson, R. R. (Ed.) The Rate and Direction of Inventive Activity: Economic and Social Factors. Princeton University Press for N.B.E.R., Princeton, pp.609-625.

Attaran, M., 1985. Industrial diversity and economic performance in U.S. areas. The Annals of Regional Science 20, pp. 44-54.

Bathelt, H., Malmberg, A. and Maskell, P., 2004. Clusters and knowledge: local buzz, global pipelines and the process of knowledge creation. Progress in Human Geography 28, 31-56.

Boschma, R. and Frenken, K., 2006. Why is economic geography not an evolutionary science? Towards an evolutionary economic geography. Journal of Economic Geography 6, 273-302.

Boschma, R. and Iammarino, S., 2009. Related variety, trade linkages, and regional growth in Italy. Economic Geography 85, 289-311.

Breschi, S. and Lissoni, F., 2001. Knowledge spillovers and local innovation systems: A critical survey. Industrial and Corporate Change 10, 975-1005.

Breschi, S. and Lissoni, F., 2009. Mobility of skilled workers and co-invention networks: an anatomy of localized knowledge flows. Journal of Economic Geography 94, 439-468.

Brower E., Kleinknecht A., 1999. Innovative output and a firm's propensity to patent. An exploration of CIS micro data. Research Policy 28, 615-624.

Burns A. F., 1934. Production trends in the United States since 1870. NBER, Boston.

Coe, D and Helpman, E., 1995. International R\&D spillovers. European Economic Review $39,859-887$. 
Cooke P., M. Uranga and G. Etxebarria, 1997. Regional innovation systems: Institutional and organizational dimensions. Research Policy 26, 475-491.

Crescenzi, R., Rodriguez-Pose, A. and Storper, M., 2007. The territorial dynamics of innovation: A Europe-United States comparative analysis. Journal of Economic Geography 673-709.

Cuneo, P. and Mairesse, J., 1984. Productivity and R\&D at the firm level in French manufacturing, in: Griliches, Z. (ed.) R\&D, Patents and Productivity. The University of Chicago Press, Chicago.

Dosi, G., 1982. Technological paradigms and technological trajectories: A suggested interpretation of the determinants and directions of technical change. Research Policy 11, $147-162$.

Elhorst, P. J., 2003. Specification and estimation of spatial panel data models. International Regional Science Review 26, 244-268.

Englander, A.S. and Mittelstädt, A.S., 1988. Total factor productivity: Macroeconomic and structural aspects of slowdown, OECD Economic Studies, 11, Summer 1988.

Fagerberg, J., 1987. A technology gap approach to why growth rates differ. Research Policy 16, 87-99.

Fleming, L., 2001. Recombinant uncertainty in technological search. Management Science 47, 117-132.

Fleming, L. and Sorenson, O., 2001. Technology as a complex adaptive system: Evidence from patent data. Research Policy 30, 1019-1039.

Freeman, C., Soete, L., 1997. The Economics of Industrial Innovation, Third edition. MIT Press, Cambridge.

Frenken, K., 2004. Entropy and information theory, in: Horst Hanusch and Andreas Pyka (eds.), The Elgar Companion to Neo-Schumpeterian Economics. Edward Elgar, Cheltenham.

Frenken, K., van Oort F.G., Verburg, T., 2007. Related variety, unrelated variety and regional economic growth. Regional Studies 41, 685-697.

Fritsch, M., 2002. Measuring the quality of regional innovation systems: A knowledge production function approach. International Review of Regional Science 25, 86-101.

Fritsch, M., 2004. Cooperation and the efficiency of regional R\&D activities. Cambridge Journal of Economics 28, 829-846.

Fritsch, M. and Franke, G., 2004. Innovation, regional knowledge spillovers and R\&D cooperation. Research Policy 33, 245-255.

Fuà G., 1983. Industrializzazione nel Nord Est e nel Centro, in: G. Fuà e C. Zacchia (ed.), Industrializzazione Senza Fratture. il Mulino, Bologna, pp. 7-46. 
Fuà, G. and Zacchia, C. (Eds.), 1983., Industrializzazione Senza Fratture, il Mulino, Bologna.

Griliches Z., 1979. Issues in assessing the contribution of research and development to productivity growth. The Bell Journal of Economics 10, 92-116.

Griliches Z. (ed.), 1984. R\&D, Patents and Productivity. The University of Chicago Press, Chicago.

Griliches, Z., 1990. Patent statistics as economic indicators: A survey. Journal of Economic Literature 28, 1661-1707.

Hall, B.H., Griliches Z. and Hausman J.A., 1986. Patents and R and D: Is there a lag?. International Economic Review 27, 265-283.

von Hayek, F.A., 1937. Economics and knowledge. Economica N.S. 4, 33-54.

Henderson, R. M., Jaffe, A. and Trajtenberg. M., 2005. patent citations and the geography of knowledge spillovers: A reassessment: Comment. American Economic Review 95, 416464.

Higòn, D. A., 2007. The impact of R\&D spillovers on UK manufacturing TFP: A dynamic panel approach. Research Policy 36, 964-979.

Jorgenson, D.W., 1995. Productivity Volume 1: Post-war US Economic Growth. MIT Press, Cambridge, MA.

Krafft, J., Quatraro F. and Saviotti P.P., 2010. Evolution of the knowledge base in knowledge intensive sectors. Industrial and Corporate Change, revised and resubmitted.

Krafft J., Quatraro F. and P., Saviotti, 2011. The knowledge base evolution in biotechnology: A social network analysis, Economics of Innovation and New Technology, forthcoming.

Kuznets S., 1930. Secular Movements in Production and Prices. Houghton Mifflin, Boston.

Lawson C. and Lorenz, E., 1999. Collective learning, tacit knowledge and regional innovative capacity. Regional Studies 33, 305-317.

Le Sage, J.P., 1999. The theory and practice of spatial econometrics, Department of Economics, University of Toledo, available at www.spatial-econometrics.org.

Lichtenberg, F., 1992. R\&D investment and international productivity differences. NBER Working Paper, no. 4161.

Lotti F. and Schivardi, F., 2005. Cross country differences in patent propensity: A firm-level investigation. Giornale degli Economisti 64, 469-502.

Maddison, A., 1987. Growth and slowdown in advanced capitalist economies: Techniques of quantitative assessment. Journal of Economic Literature 25, 649-698. 
Maleki, E., 2000. Knowledge, competence and new technology. Economics of Innovation and New Technology 9, 71-79.

Maffezzoli, M., 2006., Convergence across Italian regions and the role of technological catch up. Topics in Macroeconomics 6, Article 15.

March, J., 1991. Exploration and exploitation in organizational learning. Organization Science 2, 71-87.

Maurseth, P. B. and Verspagen, B., 2002. Knowledge spillovers in Europe: A patent citations analysis. Scandinavian Journal of Economics 104, 531-45.

Metcalfe, S.J., 2002. Knowledge for growth and the growth of knowledge. Journal of Evolutionary Economics 12, 3-15.

Nadiri, M., 1980. Contributions and determinants of research and development expenditures in the US manufacturing, in: von Furstenberg, G. (ed.) Capital, Efficiency and Growth. Ballinger, Cambridge, pp. 361-392.

Nelson, R. R., 1982. The role of knowledge in R\&D efficiency. Quarterly Journal of Economics 97, 453-70.

Nesta L., 2008. Knowledge and productivity in the world's largest manufacturing corporations. Journal of Economic Behavior and Organization 67, 886-902.

Nesta, L., and Saviotti, P.P., 2005. Coherence of the knowledge base and the firm's innovative performance: Evidence from the U.S. pharmaceutical industry. Journal of Industrial Economics 53, 123-42.

Nesta L. and Saviotti P.P., 2006. Firm knowledge and market value in biotechnology. Industrial and Corporate Change 15, 625-652.

Nightingale, P., 1998. A cognitive model of innovation. Research Policy 27, 689-709.

OECD, 2001. Measuring Productivity. Measurement of Aggregate and Industry-level Productivity Growth. OECD, Paris.

Paci, R. and Usai, S., 2009. Knowledge flows across European regions, The Annals of Regional Science 43, 669-690.

Patel, P. and Soete, L., 1988. L'évaluation des effects économiques de la technologie, STI Review 4, 133-183.

Pavitt, K., 1985. Patent statistics as indicators of innovative activities: Possibilities and problems. Scientometrics 7, 77-99.

Perroux F., 1955. Note sur la notion de 'pole de croissance'. Èconomie Appliquèe 7, 307-320. 
Pettenati, P., 1991. I Modelli di organizzazione economica del territorio, in: Fuà, (ed)., Orientamenti per la Politica del Territorio. Il Mulino, Bologna, pp.127-175.

Quatraro, F., 2009a. The diffusion of regional innovation capabilities: Evidence from Italian patent data. Regional Studies 43, 1333-1348.

Quatraro, F.. 2009b- Innovation, structural change and productivity growth. Evidence from Italian regions, 1980-2003. Cambridge Journal of Economics 33, 1001-1022..

Romijn H. and Albu, M., 2002. Innovation, networking and proximity: Lessons from small high technology firms in the UK. Regional Studies 36, 81-86.

Saviotti, P.P., 2007. On the dynamics of generation and utilisation of knowledge: The local character of knowledge. Structural Change and Economic Dynamics 18, 387-408.

Saviotti, P.P., 2004. Considerations about the production and utilization of knowledge. Journal of Institutional and Theoretical Economics 160, 100-121.

Saviotti, P.P., 1988. Information, variety and entropy in technoeconomic development. Research Policy 17, 89-103.

Schumpeter, J. A., 1939. Business Cycles. A Theoretical, Historical and Statistical Analysis of the Capitalist Process. McGraw Hill. New York and London..

Solow R. M., 1957. Technical change and the aggregate production function. The Review of Economics and Statistics 39, 312-320.

Sorenson, O., Rivkin, J.W. and Fleeming, L., 2006. Complexity, network and knowledge flows. Research Policy 35, 994-1017.

Teece, D. J., Rumelt, R. P., Dosi, G. and Winter, S., 1994. Understanding corporate coherence: Theory and evidence. Journal of Economic Behavior and Organisation 22, 627634.

Theil, H., 1967. Economics and Information Theory, North-Holland, Amsterdam..

Thomas M. J., 1975. Growth pole theory, technological change and regional economic growth. Papers in Regional Science 34, 3-25.

Ulku, H. (2007) R\&D, innovation and growth: Evidence from four manufacturing sectors in OECD countries, Oxford Economic Papers, 59, 513-535.

Usher, A., 1954. A History of Mechanical Invention. Dover, Cambridge, MA.

Verspagen, B., 1995. R\&D and productivity: A broad cross-section cross-country look. Journal of Productivity Analysis 6, 117-135.

Weitzman, M. L., 1998. Recombinant growth. Quarterly Journal of Economics 113, 331-360. 
Table 1 - Descriptive Statistics

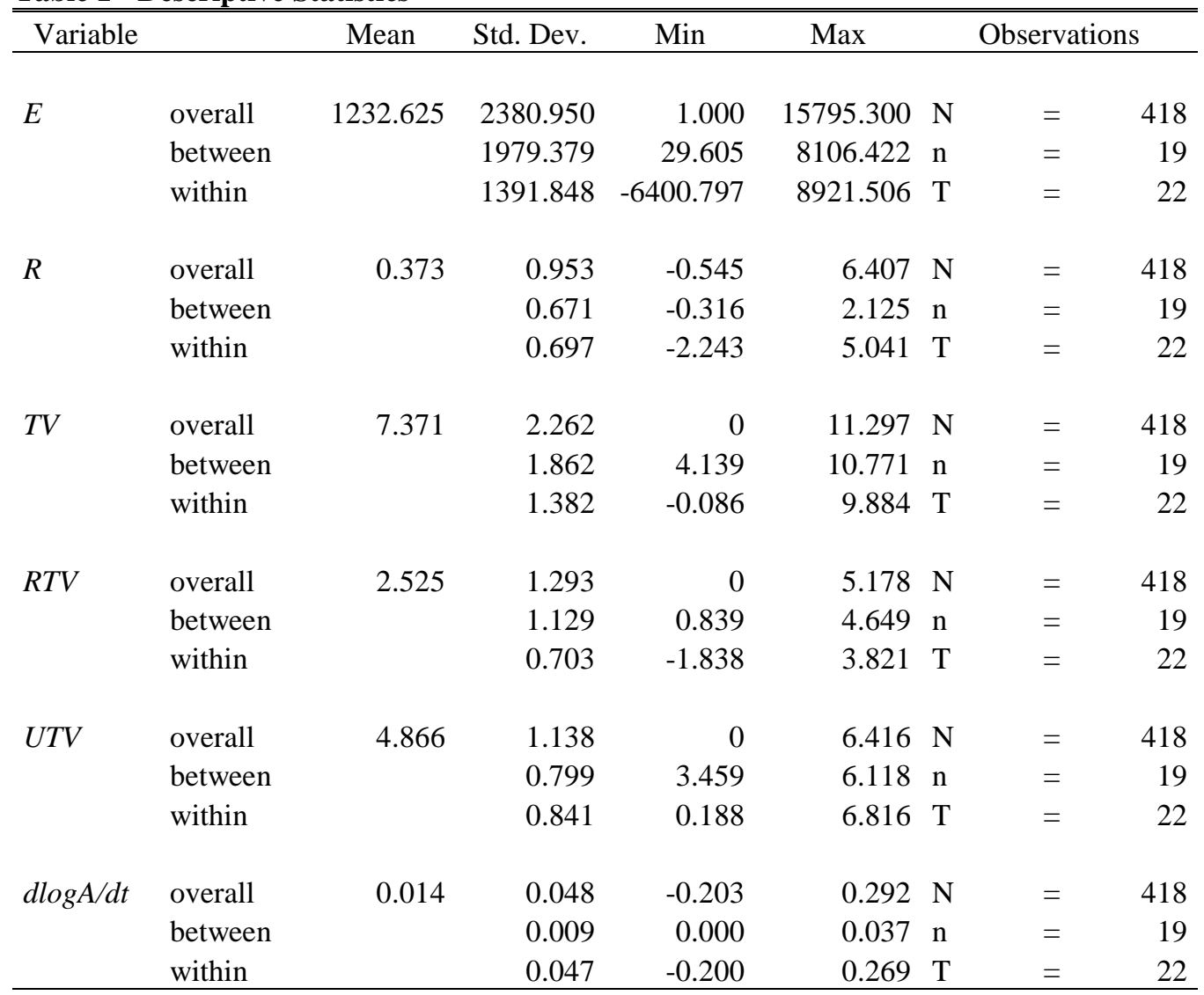

$E$ : knowledge capital; $R$ : knowledge coherence; $T V$ : information entropy; $R T V$ : within-group information entropy; $U T V$ : between-group information entropy; dlogA/dt: growth rate of multifactor productivity. 
Table 2 - Regional Decomposition of Variables (1981-2002)

\begin{tabular}{|c|c|c|c|c|c|c|}
\hline & $E$ & $R$ & $T V$ & $R T V$ & $U T V$ & $d \log A / d t$ \\
\hline Piemonte & 3860.667 & -0.316 & 10.097 & 4.340 & 5.756 & 0.007 \\
\hline Valle d'Aosta & 29.605 & 2.125 & 4.703 & 1.232 & 3.459 & 0.003 \\
\hline Liguria & 708.112 & 0.532 & 8.306 & 2.707 & 5.617 & 0.000 \\
\hline Lombardia & 8106.422 & -0.232 & 10.772 & 4.651 & 6.117 & 0.016 \\
\hline Trentino Alto Adige & 246.614 & 0.189 & 6.930 & 2.277 & 4.635 & 0.019 \\
\hline Veneto & 2088.573 & -0.206 & 9.036 & 3.654 & 5.386 & 0.023 \\
\hline Friuli Venezia Giulia & 834.670 & -0.103 & 7.846 & 2.737 & 5.118 & 0.018 \\
\hline Emilia Romagna & 2993.007 & -0.223 & 9.651 & 4.357 & 5.285 & 0.017 \\
\hline Toscana & 1219.773 & -0.155 & 8.903 & 3.161 & 5.742 & 0.011 \\
\hline Umbria & 175.860 & 0.253 & 6.676 & 1.948 & 4.766 & 0.003 \\
\hline Marche & 355.378 & 0.036 & 6.856 & 2.31 & 4.555 & 0.019 \\
\hline Lazio & 1380.175 & 0.038 & 8.934 & 3.071 & 5.876 & 0.022 \\
\hline Abruzzo & 414.795 & 0.921 & 6.161 & 2.306 & 3.828 & 0.025 \\
\hline Campania & 260.018 & 0.357 & 6.965 & 2.026 & 4.997 & 0.011 \\
\hline Puglia & 175.072 & 0.243 & 6.436 & 1.803 & 4.649 & 0.014 \\
\hline Basilicata & 34.280 & 1.496 & 4.292 & 0.8581 & 3.326 & 0.042 \\
\hline Calabria & 46.251 & 1.060 & 5.357 & 1.216 & 4.102 & 0.016 \\
\hline Sicilia & 308.488 & 0.063 & 6.387 & 1.699 & 4.661 & 0.000 \\
\hline Sardegna & 73.174 & 1.114 & 5.423 & 1.176 & 4.237 & 0.007 \\
\hline \multicolumn{7}{|c|}{$\begin{array}{l}E \text { : knowledge capital; } R: \text { knowledge coherence; } I E \text { : information entropy; } R T V \text { : within-group } \\
\text { information entropy; } U T V \text { : between-group information entropy; dlogA/dt: growth rate of } \\
\text { multifactor productivity. }\end{array}$} \\
\hline
\end{tabular}


Table 3 - Panel Data Estimates of Equation (12)

\begin{tabular}{|c|c|c|c|c|}
\hline & $(1)$ & $(2)$ & (3) & $(4)$ \\
\hline intercept & $\begin{array}{c}-0.212 * * \\
(0.093)\end{array}$ & $\begin{array}{c}0.203 * * \\
(0.93)\end{array}$ & $\begin{array}{c}-0.295 * * * \\
(0.101)\end{array}$ & $\begin{array}{c}-0.302 * * * \\
(0.102)\end{array}$ \\
\hline $\log A_{t-1}$ & $\begin{array}{l}0.0315 \\
(0.022)\end{array}$ & $\begin{array}{l}0.0223 \\
(0.021)\end{array}$ & $\begin{array}{l}0.041 * \\
(0.023)\end{array}$ & $\begin{array}{c}0.0399 * \\
(0.022)\end{array}$ \\
\hline $\log (E)_{t-1}$ & $\begin{array}{c}0.0212 * * \\
(0.009)\end{array}$ & $\begin{array}{c}0.028 * * * \\
(0.009)\end{array}$ & $\begin{array}{c}0.0185^{* *} * \\
(0.008)\end{array}$ & $\begin{array}{c}0.0173^{*} \\
(0.010)\end{array}$ \\
\hline $\log (R)_{t-1}$ & $\begin{array}{c}0.0878 * * * \\
(0.035)\end{array}$ & $\begin{array}{c}0.0792 * * \\
(0.035)\end{array}$ & $\begin{array}{c}0.0911 * * * \\
(0.035)\end{array}$ & $\begin{array}{c}0.0929 * * * \\
(0.035)\end{array}$ \\
\hline $\log (\mathrm{TV})_{\mathrm{t}-1}$ & $\begin{array}{c}0.0153 * * \\
(0.007)\end{array}$ & & & \\
\hline $\log (\text { UTV })_{\mathrm{t}-1}$ & & $\begin{array}{l}0.0007 \\
(0.001)\end{array}$ & & $\begin{array}{l}0.0011 \\
(0.002)\end{array}$ \\
\hline $\log (\mathrm{RTV})_{\mathrm{t}-1}$ & & & $\begin{array}{c}0.005 * * \\
(0.002)\end{array}$ & $\begin{array}{c}0.005 * * \\
(0.002)\end{array}$ \\
\hline $\log (\mathrm{AGGL})_{\mathrm{t}-1}$ & $\begin{array}{l}-0.0007 \\
(0.002)\end{array}$ & $\begin{array}{l}-0.0018 \\
(0.003)\end{array}$ & $\begin{array}{l}-0.0012 \\
(0.003)\end{array}$ & $\begin{array}{l}-0.0012 \\
(0.003)\end{array}$ \\
\hline $\log (\mathrm{LOQ})_{\mathrm{t}-1}$ & $\begin{array}{c}-0.1581 * * * \\
(0.032)\end{array}$ & $\begin{array}{c}-0.1506 * * * \\
(0.032)\end{array}$ & $\begin{array}{c}-0.1725 * * * \\
(0.033)\end{array}$ & $\begin{array}{c}-0.1743 * * * \\
(0.033)\end{array}$ \\
\hline Regional dummies & Yes & Yes & Yes & Yes \\
\hline Time dummies & Yes & Yes & Yes & Yes \\
\hline Rsq & 0.33 & 0.32 & 0.33 & 0.33 \\
\hline $\mathrm{F}$ & $6.55 * * *$ & $6.33 * * *$ & $6.61 * * *$ & $6.37 * * *$ \\
\hline $\mathrm{N}$ & 395 & 395 & 395 & 395 \\
\hline
\end{tabular}


Table 4 - Results for the Estimation of Equation (14) (Spatial Autoregressive Model)

\begin{tabular}{|c|c|c|c|c|}
\hline & (1) & (2) & (3) & (4) \\
\hline $\log A_{t-1}$ & $\begin{array}{c}-0.012 \\
(-0.914)\end{array}$ & $\begin{array}{l}-0.012 \\
(-0.92)\end{array}$ & $\begin{array}{l}-0.005 \\
(-0.40)\end{array}$ & $\begin{array}{l}-0.005 \\
(-0.38)\end{array}$ \\
\hline $\mathrm{W}\left[\log \left(\mathrm{A}_{\mathrm{t}} / \mathrm{A}_{\mathrm{t}-1}\right)\right]$ & $\begin{array}{c}0.188 * * \\
(1.98)\end{array}$ & $\begin{array}{c}0.188 * * \\
(1.98)\end{array}$ & $\begin{array}{c}0.190 * * \\
(1.99)\end{array}$ & $\begin{array}{c}0.190 * \\
(1.80)\end{array}$ \\
\hline $\log (E)_{t-1}$ & $\begin{array}{c}0.0145^{* *} \\
(1.99)\end{array}$ & $\begin{array}{c}0.014 * * * \\
(3.22)\end{array}$ & $\begin{array}{l}0.006 \\
(1.19)\end{array}$ & $\begin{array}{l}0.006 \\
(0.87)\end{array}$ \\
\hline $\log (R)_{t-1}$ & $\begin{array}{c}0.081 * * * \\
(2.36)\end{array}$ & $\begin{array}{c}0.081 * * \\
(2.28)\end{array}$ & $\begin{array}{c}0.091 * * * \\
(2.52)\end{array}$ & $\begin{array}{c}0.091 * * * \\
(2.51)\end{array}$ \\
\hline $\log (\mathrm{TV})_{\mathrm{t}-1}$ & $\begin{array}{l}-0.001 \\
(-0.14)\end{array}$ & & & \\
\hline $\log (\mathrm{UTV})_{\mathrm{t}-1}$ & & $\begin{array}{c}-0.0002 \\
(-0.11)\end{array}$ & & $\begin{array}{l}0.003 \\
(1.36)\end{array}$ \\
\hline $\log (\mathrm{RTV})_{\mathrm{t}-1}$ & & & $\begin{array}{l}0.003 \\
(1.36)\end{array}$ & $\begin{array}{l}0.0002 \\
(0.147)\end{array}$ \\
\hline $\log (\mathrm{AGGL})_{\mathrm{t}-1}$ & $\begin{array}{c}-0.005 * * * \\
(-4.15)\end{array}$ & $\begin{array}{c}-0.004 * * * \\
(-4.15)\end{array}$ & $\begin{array}{c}-0.004 * * * \\
(-4.22)\end{array}$ & $\begin{array}{c}-0.004 * * * \\
(-4.21)\end{array}$ \\
\hline $\log (\mathrm{LOQ})_{\mathrm{t}-1}$ & $\begin{array}{c}-0.131 * * * \\
(-4.08)\end{array}$ & $\begin{array}{c}-0.131 * * * \\
(-4.09)\end{array}$ & $\begin{array}{c}-0.143 * * * \\
(-4.32)\end{array}$ & $\begin{array}{c}-0.144 * * * \\
(-4.31)\end{array}$ \\
\hline Regional dummies & Yes & Yes & Yes & Yes \\
\hline Time dummies & Yes & Yes & Yes & Yes \\
\hline Log-likelihood & 653.18 & 653.17 & 663.4 & 654.07 \\
\hline $\mathrm{N}$ & 395 & 395 & 395 & 395 \\
\hline
\end{tabular}


Table 5 - Results for the Estimation of Equation (15) (Spatial Error Model)

\begin{tabular}{|c|c|c|c|c|}
\hline & (1) & (2) & (3) & (4) \\
\hline $\log \mathrm{A}_{\mathrm{t}-1}$ & $\begin{array}{l}-0.013 \\
(-0.94)\end{array}$ & $\begin{array}{c}-0.019 * \\
(-1.79)\end{array}$ & $\begin{array}{l}-0.005 \\
(-0.36)\end{array}$ & $\begin{array}{l}-0.005 \\
(-0.36)\end{array}$ \\
\hline $\log (E)_{t-1}$ & $\begin{array}{c}0.016 * * \\
(2.22)\end{array}$ & $\begin{array}{c}0.009 * * * \\
(3.29)\end{array}$ & $\begin{array}{c}0.010^{*} \\
(1.68)\end{array}$ & $\begin{array}{l}0.008 \\
(1.17)\end{array}$ \\
\hline $\log (R)_{t-1}$ & $\begin{array}{c}0.083 * * * \\
(2.41)\end{array}$ & $\begin{array}{c}0.033 \\
(1.102)\end{array}$ & $\begin{array}{c}0.092 * * * \\
(2.58)\end{array}$ & $\begin{array}{c}0.093 * * * \\
(2.60)\end{array}$ \\
\hline $\log (\mathrm{TV})_{\mathrm{t}-1}$ & $\begin{array}{c}0.001 \\
(0.160)\end{array}$ & & & \\
\hline $\log (\mathrm{UTV})_{\mathrm{t}-1}$ & & $\begin{array}{c}-0.0002 \\
(-0.54)\end{array}$ & & $\begin{array}{c}0.0006 \\
(0.39)\end{array}$ \\
\hline $\log (\text { RTV })_{t-1}$ & & & $\begin{array}{l}0.003 \\
(1.39)\end{array}$ & $\begin{array}{l}0.003 \\
(1.45)\end{array}$ \\
\hline $\log (A G G L)_{t-1}$ & $\begin{array}{c}-0.006 * * * \\
(-4.59)\end{array}$ & $\begin{array}{c}-0.002 * * * \\
(-2.55)\end{array}$ & $\begin{array}{c}-0.006 * * * \\
(-4.75)\end{array}$ & $\begin{array}{c}-0.006 * * * \\
(-4.69)\end{array}$ \\
\hline $\log (\mathrm{LOQ})_{\mathrm{t}-1}$ & $\begin{array}{c}-0.126 * * * \\
(-4.02)\end{array}$ & $\begin{array}{l}0.005 \\
(0.52)\end{array}$ & $\begin{array}{c}-0.138 * * * \\
(-4.25)\end{array}$ & $\begin{array}{c}-0.139 * * * \\
(-4.27)\end{array}$ \\
\hline Spatial autocorrelation & $\begin{array}{c}0.50 * * * \\
(6.82)\end{array}$ & $\begin{array}{c}0.48 * * * \\
(6.22)\end{array}$ & $\begin{array}{c}0.51 * * * \\
(7.12)\end{array}$ & $\begin{array}{c}0.50 * * * \\
(6.91)\end{array}$ \\
\hline Regional dummies & Yes & Yes & Yes & Yes \\
\hline Time dummies & Yes & Yes & Yes & Yes \\
\hline Log-likelihood & 661.99 & 636.58 & 662.96 & \\
\hline $\mathrm{N}$ & 395 & 395 & 395 & 395 \\
\hline
\end{tabular}




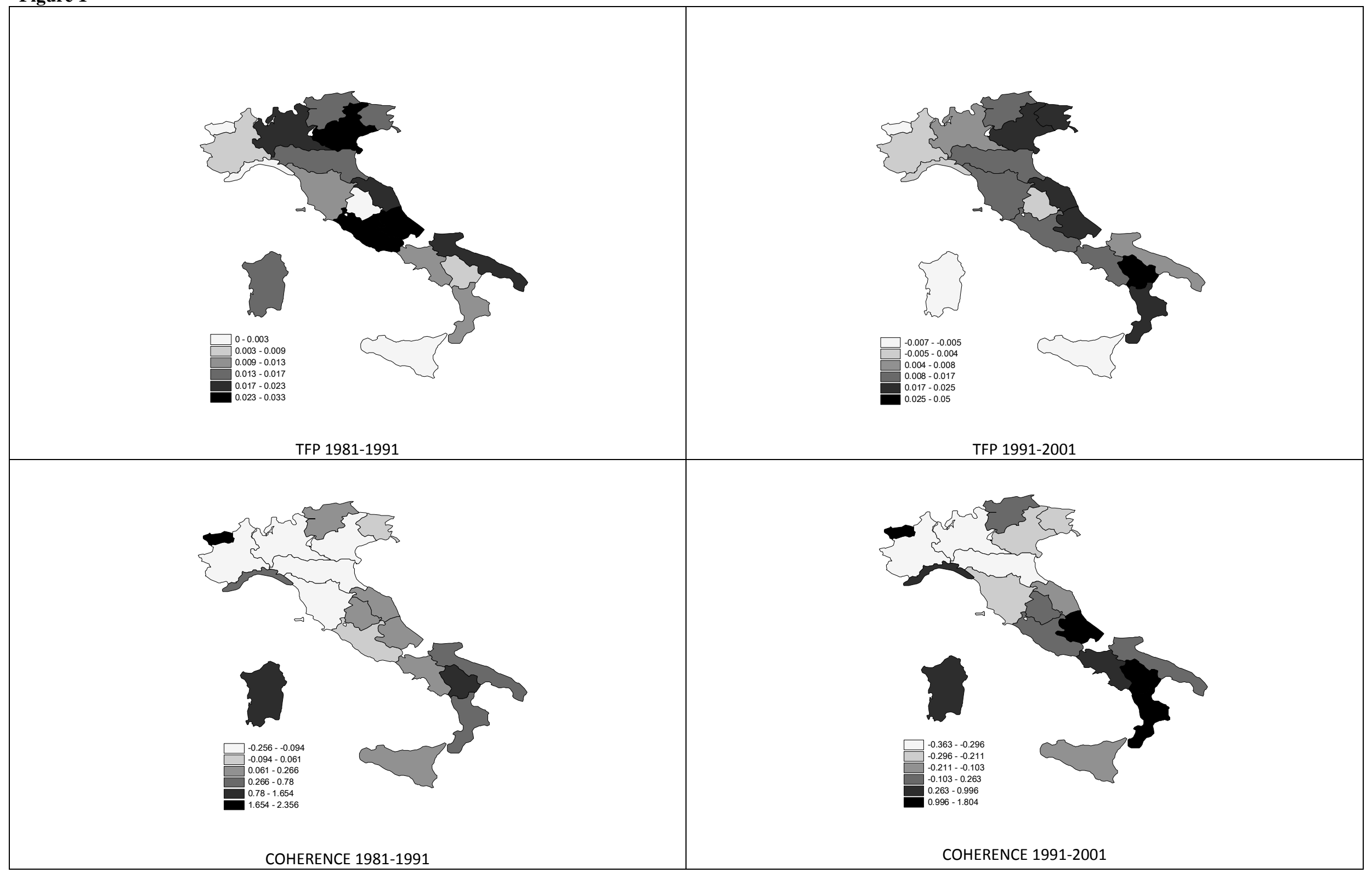


